\title{
The Paradox of In-Group Love: Differentiating Collective Narcissism Advances Understanding of the Relationship Between In-Group and Out-Group Attitudes
}

Journal of Personality 81:I, February 2013 (C) 2012 The Authors

Journal of Personality @ 2012,

Wiley Periodicals, Inc.

DOI: 10.1 I I I/j. I 467-6494.20I2.00779.x

\author{
Agnieszka Golec de Zavala, 'Aleksandra Cichocka, ${ }^{2}$ and \\ Michał Bilewicz ${ }^{2}$ \\ 'Lisbon University Institute \\ ${ }^{2}$ University of Warsaw
}

\begin{abstract}
Objective: The present studies test the hypothesis that the overlap between collective narcissism and positive in-group identification conceals the opposite relationships these variables have with out-group derogation.

Method: Five surveys were conducted in different cultural and national contexts, using different samples and different intergroup contexts (Study I, Polish student sample, $N=85$; Study 2, British student sample, $N=81$; Study 3, Polish representative sample, $N=979$; Study 3, Polish student sample, $N=267$ and Study 5, British student sample, $N=24$ I).

Results: The results of suppression analyses systematically indicate that when the positive relationship between collective narcissism and in-group positivity is controlled for, the non-narcissistic in-group positivity predicts less out-group negativity, whereas collective narcissism predicts more out-group derogation.

Conclusions: The results advance our understanding of constructive and destructive forms of in-group positivity and their different consequences for intergroup attitudes.
\end{abstract}

Keywords: collective narcissism, in-group positivity, out-group negativity

"He who loves not his country, can love nothing," wrote George Byron in one of his historical tragedies (1822, p. 80). Romantic poets, writers, and philosophers have linked positive regard for one's own national group with positive attitudes toward other nations. In individual psychology, self-liking is often seen as a precondition of social inclusion and secure attachment to others (e.g., Bowlby, 1982). However, this reasoning is distant from the key theoretical insights of psychological research on intergroup relations. One of the basic tenets of social identity theory is that people discriminate against other groups because their positive self-esteem is derived from positive social identities based on favorable comparisons with other groups. This theoretical tradition proposes that (a) outgroup derogation elevates self-esteem and (b) striving for positive self-esteem motivates out-group derogation (e.g., Abrams \& Hogg, 1988; Tajfel \& Turner, 1986). The more valued and important a group is to the self and the more people identify with it, the more they would derogate other groups to maintain this positive social identity. Thus, from this perspective, high in-group identification and positive attitudes toward one's ingroup are rarely perceived as a potential for positive attitudes toward other groups.
Several empirical studies have confirmed the positive relationship between high identification with an in-group and derogation of out-groups (see, e.g., Aberson, Healy, \& Romero, 2000 , for a review). However, meta-analyses and reviews conclude that this relationship is inconsistent and, across studies, averages close to zero (e.g., Hinkle \& Brown, 1990; Jackson, Brown, Brown, \& Marks, 2001; Pehrson, Brown, \& Zagefka, 2009). Similarly, research on individuals' positive evaluations of their social identities conceptualized as high collective selfesteem has generated mixed findings. The findings variously indicate positive, negative, or nonsignificant relationships

Portions of this article were presented at the annual meeting of the International Society of Political Psychology, in San Francisco, July 2010. Studies 2 and 5 were supported by British Academy grant SG090532 awarded to Agnieszka Golec de Zavala. Michał Bilewicz and Aleksandra Cichocka were supported by the Foundation for Polish Science (FOCUS program).

We would like to thank Christopher M. Federico, John T. Jost, Robert Schatz, and Virginia Newton for their very helpful comments on earlier versions of this article.

Correspondence concerning this article should be addressed to Agnieszka Golec de Zavala at CIS/ISCTE IUL, Avenida das Forças Armadas, Edificio ISCTE, 1649026 Lisboa, Portugal. Email: agnieszka.golec@gmail.com. 
between high collective self-esteem and out-group negativity (Crocker \& Luhtanen, 1990; Hunter etal., 2005; Long \& Spears, 1998; Luhtanen \& Crocker, 1992; for a review, see Rubin \& Hewstone, 1998).

We argue that the reason for this inconsistency lies in the overlap between genuine in-group positivity and collective narcissism defined as a belief in the exaggerated greatness of one's in-group contingent on external validation (Golec de Zavala, Cichocka, Eidelson, \& Jayawickreme, 2009). Collective narcissism predicts out-group derogation and suppresses the potential of non-narcissistic positive regard for an in-group to predict positive attitudes toward out-groups. Before we outline our hypotheses in more detail, we will discuss the research on constructive and destructive forms of in-group positivity and findings regarding the relationship between collective narcissism and out-group derogation.

\section{In-Group Positivity and Out-Group Derogation}

Political psychologists have been among the first to suggest that not all forms of "in-group love" are associated with "outgroup hate." They differentiate between more and less belligerent forms of positive national feelings. Both forms overlap in positive evaluation of one's nation but make different predictions for attitudes toward national out-groups. For example, Kosterman and Feshbach (1989) differentiate between patriotism (positive attachment to a nation) and nationalism ("national superiority and an orientation toward national dominance"; $p$. 261). Empirical studies indicate that nationalism predicts outgroup hostility, support for militarism, and international isolationism, whereas patriotism is typically unrelated to negative out-group attitudes (de Figueiredo \& Elkins, 2003; Kosterman \& Feshbach, 1989). Schatz, Staub, and Lavine (1999) differentiate between constructive and blind patriotism. Constructive patriotism reflects mature attachment to a country that accepts national vices and the possibility of national betterment. Blind patriotism reflects rigid national attachment characterized by uncritical positive evaluation of the nation. Only blind patriotism is reliably linked to derogation of national out-groups. Constructive patriotism does not predict out-group derogation. Several studies also reported a negative relationship between constructive patriotism and militarism (McCleary, Nalls, \& Williams, 2009).

We argue that differentiating the narcissistic aspect of ingroup positivity may shed new light on the link between ingroup positivity and out-group derogation. We argue that the various conceptualizations and operationalizations of in-group positivity proposed in the literature capture both narcissistic and non-narcissistic aspects of positive in-group feelings and yield inconclusive results regarding the link between in-group positivity and out-group derogation. Collective narcissism is related to out-group negativity and may suppress the potential of the self-contained, noncontingent appreciation of an ingroup to predict positive attitudes toward out-groups. At the same time, the overlap between collective narcissism and genuine in-group positivity may ease the collective narcissistic hostility toward those who do not validate the in-group's positive image. Our argument extends beyond the context of a national in-group because people can narcissistically identify with almost any social group. Below we report recent evidence reliably relating collective narcissism to out-group negativity.

\section{Collective Narcissism and Positive In-Group Identification}

Collective narcissism is a counterpart of individual narcissism at the level of social identity (Golec de Zavala etal., 2009). It captures the capacity of excessive group esteem to inspire out-group hostility. Collective narcissism predicts intergroup aggressiveness and out-group prejudice over and above other robust predictors. The relationship between collective narcissism and out-group hostility is driven by the narcissistic susceptibility to the in-group image being threatened.

For example, in an American sample examined in 2005, collective narcissism predicted support for the war in Iraq in response to terrorist threat over and above social dominance orientation, authoritarianism, blind patriotism, nationalism, and in-group glorification, or a belief in the in-group's superiority. The positive relationship between collective narcissism and support for the war in Iraq was mediated by perceived threat to the in-group (Golec de Zavala, 2011; Golec de Zavala etal., 2009). Polish collective narcissists reported aggressive behavioral tendencies toward French people after they were led to believe that a French person criticized Poland (Golec de Zavala \& Cichocka, 2011). Collective narcissists reported higher levels of anti-Semitism because they perceived their nation as threatened and Jews as a particularly threatening out-group (Golec de Zavala \& Cichocka, 2012).

Collective narcissists are constantly vigilant and sensitive to anything that may undermine the in-group's image, arguably because unacknowledged internal doubts underlie narcissistic exaggerated group image. Research shows that collective narcissism is predicted by a combination of high explicit and low implicit collective self-esteem. Collective narcissists interpret even ambiguous out-group actions as threatening to the ingroup's image (Golec de Zavala etal., 2009).

\section{Overview of the Present Studies}

In the present studies, we examine different conceptualizations and operationalizations of in-group positivity utilized by previous research to demonstrate that these measures typically capture both narcissistic and non-narcissistic aspects of positive group regard. We predict that when collective narcissism is taken into account in the analyses, the weak and nonsignificant direct relationship between in-group positivity and outgroup negativity should become more strongly negative and statistically significant. In other words, non-narcissistic ingroup positivity should significantly predict positive attitudes 
toward out-groups when its overlap with collective narcissism is accounted for. We predict also that the non-narcissistic aspect of in-group positivity suppresses the relationship between collective narcissism and out-group negativity. When the overlap between in-group positivity and collective narcissism is controlled for, collective narcissism should become a stronger positive predictor of out-group derogation.

Controlling for the narcissistic aspect of positive in-group identification removes the narcissistic need to assert the privileged position and positive evaluation of the in-group and its contingency on external recognition of the in-group. Thus, in-group positivity without a narcissistic aspect is a confident and genuine positive evaluation and an unpretentious pride of one's in-group. On the other hand, removing positive in-group identification from collective narcissism means taking away the joy of being a member of a valued in-group and leaving only the concern about what the in-group amounts to in the eyes of others. Thus, controlling for the narcissistic aspect of positive in-group love allows the observation of the intergroup effects of both the genuine in-group positivity and uninhibited collective narcissistic zeal.

Following previous studies that examined the relationship between individual narcissism, genuine self-esteem, and antisocial behavior (e.g., Donnellan, Trzesniewski, Robins, Moffitt, \& Caspi, 2005; Paulhus, Robins, Trzesniewski, \& Tracy, 2004), we use suppression analyses to control for the overlap between collective narcissism and in-group positivity. Suppression takes place when the inclusion of a suppressor in the analysis of the relationship between a predictor and an outcome variable strengthens or changes the direction of the relationship between the predictor and the outcome. Thus, a suppressor is a variable that contains the predictive ability of the predictor (Cohen, Cohen, West, \& Aiken, 2003). After inclusion in the regression equation, a suppressor "increases the predictive validity of another variable" (Conger, 1974, pp. 36-37) and allows the initial effect to rise to its "true" level (MacKinnon, Krull, \& Lockwood, 2000; Paulhus etal., 2004). When two variables are mutual suppressors, each predictor acts as a suppressor for the relationship the other has with the outcome variable. Not only does the suppressor strengthen the relationship of the predictor with the outcome variable, but also the predictor strengthens or changes the relationship between the suppressor and the outcome variable (Tzelgov \& Henik, 1991).

The relationship between individual narcissism, genuine self-esteem, and antisocial behavior is an example of mutual suppression. Individual narcissism and genuine self-esteem overlap in their generally positive opinion about the self (e.g., Baumeister, Campbell, Krueger, \& Vohs, 2003). Adding individual narcissism to the regression equation reveals negative effects of self-esteem on antisocial behavior. At the same time, adding self-esteem to the regression equation strengthens the positive effect of narcissism on antisocial behavior (e.g., Paulhus etal., 2004). Thus, narcissistic exaggeration of the self-image without genuine, positive self-esteem predicts interpersonal hostility and delinquency. Positive, non-narcissistic self-esteem predicts a decrease in these forms of antisocial behavior. We propose that just as one can distinguish between narcissistic and genuine personal self-esteem and look at their relationships with interpersonal aggressiveness, it is possible to differentiate between narcissistic and non-narcissistic, genuine positive regard for one's group and examine their opposite relationships with out-group derogation.

In all studies, we examine suppression effects of collective narcissism and of positive group regard using the procedure to test indirect effects (MacKinnon etal., 2000; Preacher \& Hayes, 2004, 2008a). In our analyses we used the bootstrapping method (see Hayes, 2009, for more information about this procedure) to probe the significance of the suppression effects (MacKinnon et al., 2000). For each of the suppression effects, we computed bias-corrected $95 \%$ confidence intervals. We requested 10,000 bootstrap samples. The point estimates, confidence intervals, and effect sizes for all studies are presented in Table 1. In all studies, the patterns of results were the same when controlling for age and gender and when out-groups were analyzed separately.

\section{STUDY I}

In Study 1, we explored the relationship between collective self-esteem, collective narcissism, and negative out-group attitudes in Poland. We measured attitudes toward two out-groups typically perceived as threatening in this national context: Jews and Germans. We also measured attitudes toward two out-groups whose threatening actions were salient at the time the study was conducted: Arabs (because of terrorist threat) and Chinese (because of the aggressive actions of the Chinese government before the Olympic Games in Beijing).

\section{Method}

\section{Participants}

Participants were 85 undergraduate students in Poland. All participants reported Polish nationality; 61 were female and 24 were male, with mean age of $21.19(S D=1.53)$.

\section{Measures}

Collective self-esteem. Collective self-esteem $(\alpha=.86$, $M=4.75, S D=1.08$ ) was assessed using the Collective SelfEsteem Scale with reference to a national group (Luhtanen \& Crocker, 1992). Participants used a 7-point scale ( $1=$ I strongly disagree and $7=I$ strongly agree). We created a composite measure of the Private and Identity subscales to capture positive group regard as a combination of positive evaluation of the national group and its importance for one's identity, $r(83)=.65, p<.001$. However, analyses including all subscales of the Collective Self-Esteem Scale confirmed the same pattern of results. 


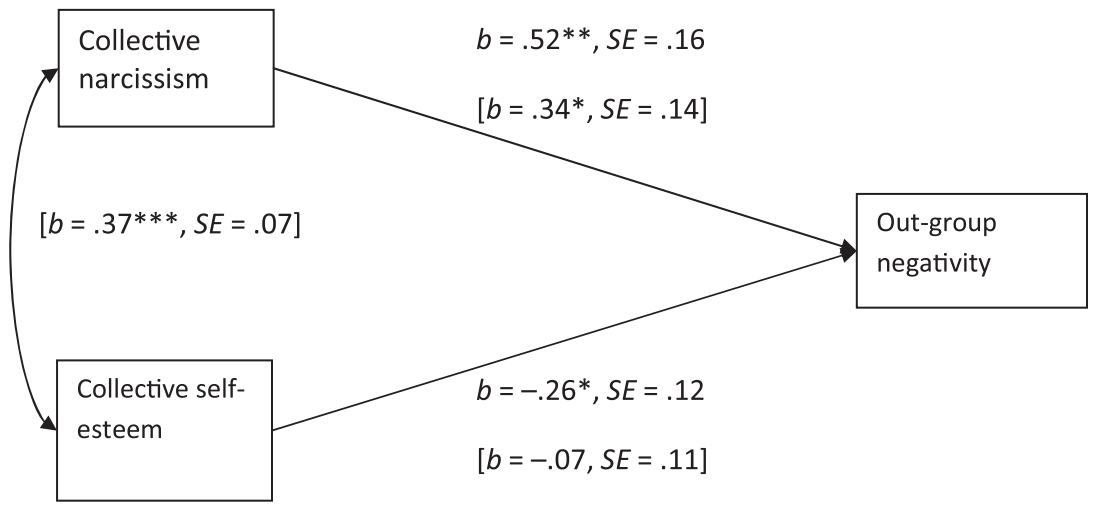

Figure I Suppressor effect of collective self-esteem and collective narcissism on out-group negativity (Study I; $N=85$ ). Entries are unstandardized regression coefficients. Results for simple regressions are presented in brackets.

$* p<.05$. ** $p<.01$. ${ }^{* * *} p<.001$.

Collective narcissism. Collective narcissism ( $\alpha=.86$, $M=3.52, S D=.80$ ) was measured by the Collective Narcissism Scale with reference to a national group (Golec de Zavala etal., 2009). Participants used a 6-point scale ranging from 1 (I strongly disagree) to 6 (I strongly agree).

Out-group negativity. Out-group negativity was measured by six semantic differentials describing feelings toward the out-groups (e.g., cold-warm, respect-contempt; Wright, Aron, McLaughlin-Volpe, \& Ropp, 1997). Possible answers ranged from 1 to 8 , and they were coded so that higher scores indicate more negative feelings ( $\alpha$ s ranged from .93 to .94). Scores for all out-groups were positively correlated (Pearson's $r s$ ranged from .32 to .51 ; all $p \mathrm{~s}<.05$ ). We created a composite score of out-group negativity by averaging the mean scores $(\alpha=.75$, $M=3.94, S D=1.05$ ).

\section{Results and Discussion}

The correlation between collective self-esteem and out-group negativity was negative and nonsignificant, $r(83)=-.07$, $p=.54$. Collective narcissism was positively related to outgroup negativity, $r(83)=.26, p=.02$. Collective narcissism was positively correlated with collective self-esteem, $r(83)=.50$, $p<.001$.

In order to test the mutual suppression hypothesis, we performed a series of multiple regression analyses using outgroup negativity as the outcome variable. First, out-group negativity was regressed on collective self-esteem (see the results in brackets for the effect of collective self-esteem on out-group negativity in Figure 1). Collective self-esteem was unrelated to out-group attitudes. Next, the out-group negativity was regressed onto collective narcissism. Collective narcissism significantly positively predicted out-group derogation (see the results in brackets for the effect of collective narcissism on out-group negativity in Figure 1). Then outgroup negativity was regressed on the predictor and the suppressor simultaneously. The full model was significant, $F(2,80)=5.38, R^{2}=.12, p=.01$. The negative relationship between collective self-esteem and out-group negativity became stronger and significant (see Figure 1). The amount of explained variance increased significantly in comparison to the model with collective self-esteem as a sole predictor, $\Delta R^{2}=.11$, $p=.01$.

The initial positive relationship between collective narcissism and out-group negativity strengthened (see Figure 1). The amount of variance explained by the model with two predictors significantly increased in comparison to the model with collective narcissism as a sole predictor, $\Delta R^{2}=.05, p=.03$. Suppression effects of collective narcissism and collective self-esteem were significant (see the point and interval estimates of the suppression effect and its effect sizes in Table 1).

The results of Study 1 provide initial support for our proposition that controlling the overlap between in-group positivity and collective narcissism reveals the opposite relationships these variables have with out-group derogation. When the overlap between collective narcissism and collective selfesteem was accounted for, the positive relationship between collective narcissism and out-group negativity significantly strengthened. Importantly, a negative association between collective self-esteem and out-group derogation became significant. With collective narcissism partialed out, low collective self-esteem predicts out-group negativity, whereas high collective self-esteem is related to positive out-group attitudes.

Although encouraging, the results of Study 1 demonstrated the mutual suppression effects of collective narcissism and only one form of positive group regard out of several discussed in the literature. In Study 2, we aimed to replicate these results operationalizing positive group regard as high in-group identification. We propose that both conceptualizations of in-group positivity capture essentially similar phenomena and both conflate narcissistic and non-narcissistic aspects of in-group favoritism. In order to provide further evidence of generalizability of our findings, we conducted Study 2 in a different national context. 
Table I Studies I-5: Point and Interval Estimates of the Suppression Effects and Their Effect Sizes

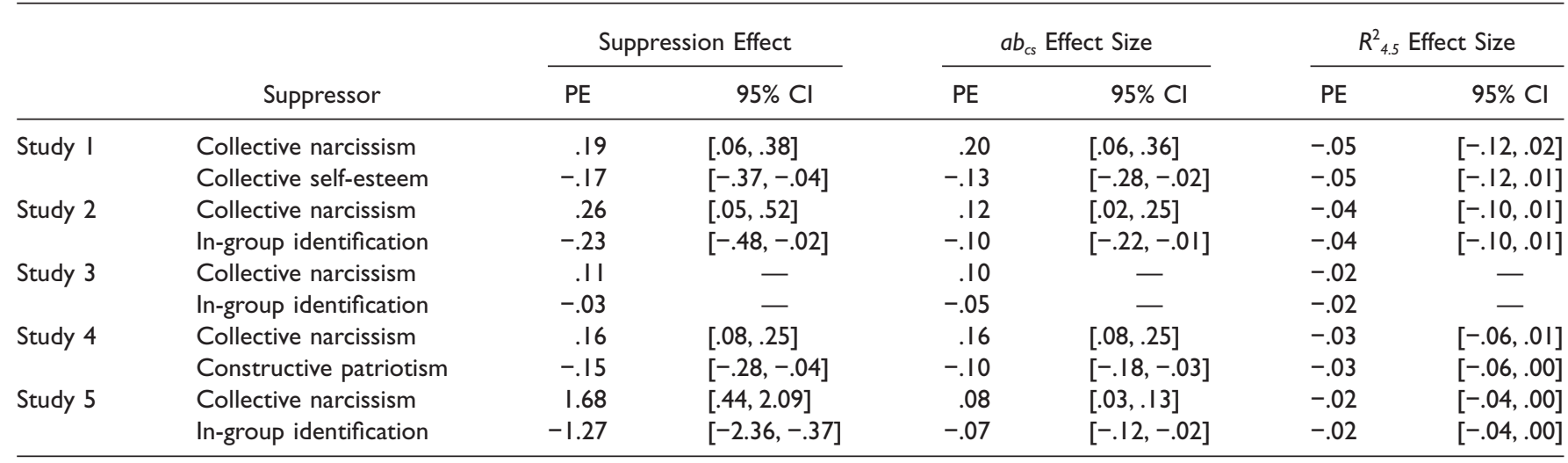

Note. $\mathrm{PE}=$ point estimate; $\mathrm{Cl}=$ bias-corrected bootstrapped confidence interval. For each suppression effect, we report two indices of effect size (Preacher \& Kelley, 20I I). We use the $a b_{c s}$ index (Preacher \& Hayes, 2008b) because it is fully standardized and insensitive to the scales on which the studied variables are assessed. We also report the $R_{4.5}^{2}$ index of explained variance interpreted as the overlap of the variances of the predictor and the dependent variable that also overlaps with the variance of the suppressor (Preacher \& Kelley, 20I I). A negative value of $R_{4.5}^{2}$ can indicate a suppression effect (Fairchild, MacKinnon, Taborga, \& Taylor, 2009). In Study 3 , the $95 \%$ Cls are not reported because of the sufficiently large number of participants (Fritz \& MacKinnon, 2007). Both suppression effects in Study 3 were significant, with $p s<.00$ I.

\section{STUDY 2}

\section{Method}

\section{Participants}

Participants were 81 undergraduate students who identified themselves as British. Fifteen participants were male and 66 female. Their mean age was $22.33(S D=5.64)$. Sixty-three percent of participants reported themselves to be ethnically White, $15 \%$ identified as Black, and $22 \%$ as "other."

\section{Measures}

In-group identification. In-group identification $(\alpha=.77$, $M=4.40, S D=1.22$ ) was measured with three items: "Being a British is an important part of my identity," "My national group is an important reflection of who I am," and "I'm glad to be a member of my national group" (see Crisp, Stone, \& Hall, 2006). Participants were asked to what extent they agree with this statement on a scale from 1 (I strongly disagree) to 7 (I strongly agree).

Collective narcissism. Collective narcissism $(\alpha=.83$, $M=3.25, S D=1.04$ ) was measured as in Study 1 with reference to a group defined as "British people."

Out-group negativity. Out-group negativity was measured with Feeling Thermometers (Alwin, 1997). Participants indicated their feelings toward two groups that for historical and political reasons are negatively evaluated and perceived as out-groups in Great Britain: Germans and Belgians. The scale ranged from $0\left(0^{\circ}=\right.$ extremely unfavorable feelings $)$ to 9 $\left(100^{\circ}=\right.$ extremely favorable feelings $)$. To maintain coherence with Study 1, data were recoded so that higher scores indicate more negative feelings toward out-groups. Scores for both out-groups were positively correlated, $r(77)=.71, p<.001$. We created a composite score of out-group attitudes $(M=3.56$, $S D=2.37$ ).

\section{Results}

The relationship between in-group identification and outgroup negativity was negative and nonsignificant, $r(78)=-.11$, $p=.32$. Collective narcissism was positively correlated with out-group negativity, $r(78)=.23, p=.04$. Collective narcissism was positively correlated with in-group identification, $r(79)=.40, p<.001$.

As in Study 1, out-group negativity was first regressed on national in-group identification. The relationship was negative and nonsignificant. Next, the out-group negativity was regressed on collective narcissism. Collective narcissism significantly positively predicted out-group derogation. Then outgroup negativity was regressed on in-group identification and collective narcissism simultaneously. The full model was significant, $F(2,77)=4.55, R^{2}=.11, p=.02$.

When collective narcissism was added to the equation containing only in-group identification, the negative relationship between in-group identification and out-group negativity strengthened and became significant, $\Delta R^{2}=.09, p=.01$. The positive relationship between collective narcissism and outgroup negativity strengthened significantly when in-group identification was added to the equation with collective narcissism as a sole predictor, $\Delta R^{2}=.05, p=.04$ (see Figure 2). The suppression effects of collective narcissism and national ingroup identification were significant (see Table 1).

Study 2 corroborated the findings of Study 1 in a different national context and with a different operationalization of in-group positivity. The results confirmed that collective narcissism and high in-group identification acted as mutual 


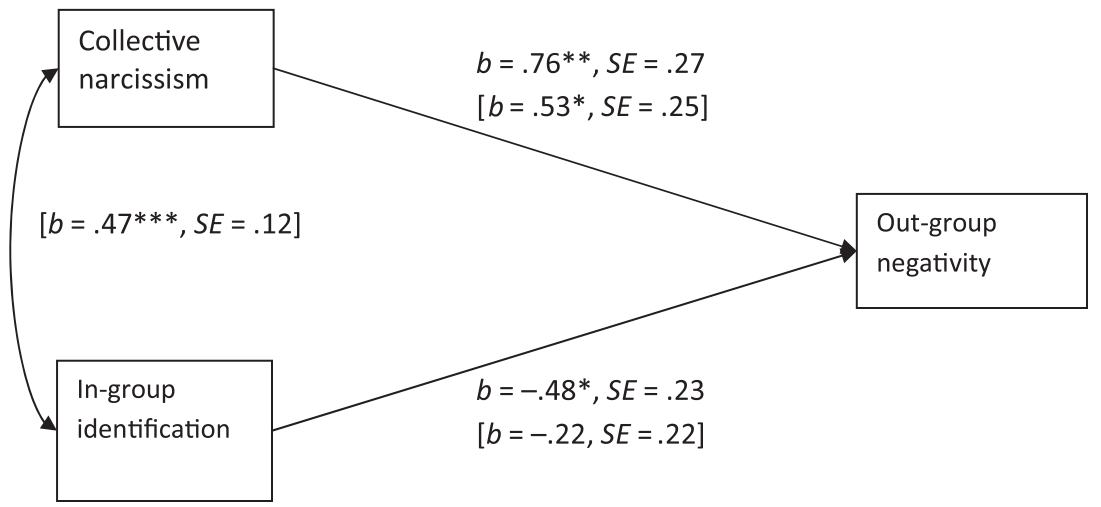

Figure 2 Suppressor effect of in-group identification and collective narcissism on out-group negativity (Study 2; N=8I). Entries are unstandardized regression coefficients. Results for simple regressions are presented in brackets.

$* p<.05 . * * p<.01$. $* * * p<.001$.

suppressors in predicting out-group negativity. The results of Studies 1 and 2 were obtained from relatively small student samples that might be limited in their representativeness and limit generalizability of our findings. Thus, in Study 3 we aimed to replicate our results in a representative sample of Polish adults.

\section{STUDY 3}

\section{Method}

\section{Participants}

Participants were a representative sample of 979 adults living in Poland. Study 3 was administered as part of the Polish Prejudice Survey conducted in 2009. Data from five participants were excluded from the analyses because they reported their nationality as Belarusian $(n=4)$ or Ukrainian $(n=1)$. The final sample included 974 Polish participants, with a mean age of $46.26(S D=18.25) ; 52.7 \%$ were women.

\section{Measures}

Positive in-group identification. Positive in-group identification ( $\alpha=.81, M=3.98, S D=.62)$ was measured using the Social Identification Scale (Cameron, 2004). Items reflected positive opinion about the in-group (e.g., "In general I'm glad to be Polish"), centrality of the in-group to one's identity (e.g., "I often think about being Polish"), and strength of ties with the group (e.g., "I have a lot in common with other Polish people"). Participants were asked to think about their national group while responding to these items using a scale ranging from 1 (definitely disagree) to 5 (definitely agree).

Collective narcissism. Collective narcissism $(\alpha=.84$, $M=3.99, S D=1.18$ ) was measured by a five-item version of the Collective Narcissism Scale (Luhtanen \& Crocker, 1992). Participants were asked to think about their national group while indicating their answers.
Out-group negativity. Out-group negativity was measured using a Bogardus-type social distance scale (e.g., Bogardus, 1925; Goff, Steele, \& Davies, 2008). Participants were asked to indicate the extent to which they would accept a minority member as their coworker, neighbor, or spouse of a family member on a 4-point scale ranging from 1 (definitely against) to 4 (definitely accept). Scores were recoded so that higher scores indicate more negative attitudes toward minorities. The measure was administered for the seven most significant minority out-groups typically perceived as threatening the economic and/or political status of the Polish majority: Germans, Jews, Russians, Belarusians, Ukrainians, Gypsies, and Vietnamese. The alphas for the scales ranged from .78 to .83 . Since scale scores for all minorities were strongly correlated (Pearson's $r$ s ranged from .63 to .91 , all $p s<.001$ ), we created a composite index of out-group negativity by averaging scores for all out-groups $(\alpha=.97, M=2.10, S D=.68)$.

\section{Results}

The relationship between in-group identification and outgroup negativity was negative and nonsignificant, $r(966)=-.04$, $p=.23$. Collective narcissism was positively related to outgroup negativity, $r(965)=.27, p<.001$. Collective narcissism was positively correlated with positive in-group identification, $r(969)=.33, p<.001$.

As in previous studies, out-group negativity was first regressed on in-group identification. The relationship was positive and nonsignificant. Next, the out-group negativity was regressed on collective narcissism. Collective narcissism significantly positively predicted out-group derogation. Then out-group negativity was regressed on positive in-group identification and collective narcissism simultaneously. The full model was significant, $F(2,963)=47.66, R^{2}=.07$. When collective narcissism was added to the equation containing only in-group identification, the negative relationship between in-group identification and out-group negativity became significant, $\Delta R^{2}=.02, p<.001$. The positive relationship 


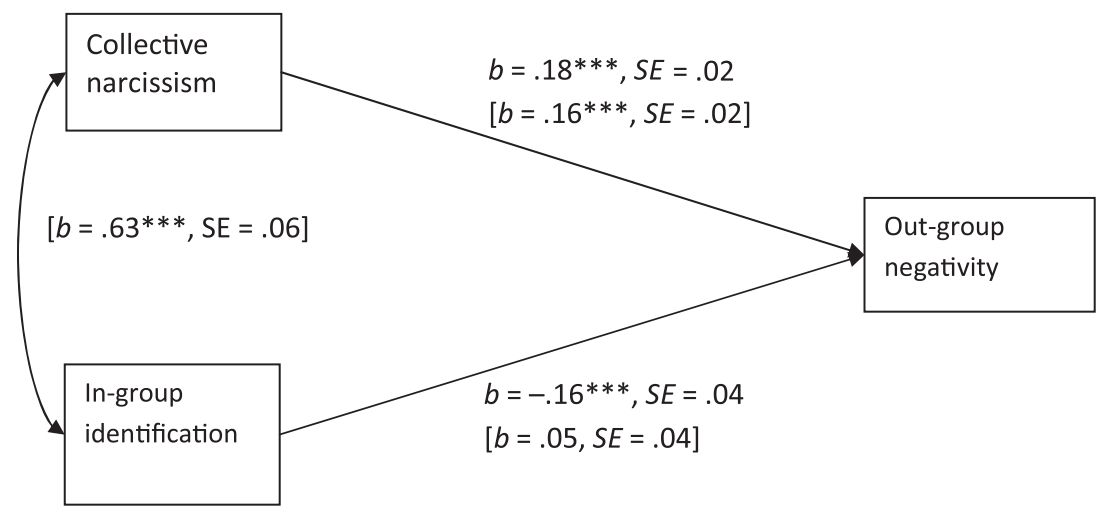

Figure 3 Suppressor effect of in-group identification and collective narcissism on out-group negativity (Study 3; N=974). Entries are unstandardized regression coefficients. Results for simple regressions are presented in brackets. $* * * p<.001$.

between collective narcissism and out-group negativity strengthened when in-group identification was added to the equation with collective narcissism as a sole predictor, $\Delta R^{2}=.09, p<.001$ (see Figure 3). The suppression effects of collective narcissism and positive in-group identification were significant (see Table 1).

The results of Study 3 replicate the findings of Studies 1 and 2, confirming that when the common variance of positive in-group identification and collective narcissism is controlled for, collective narcissism predicts out-group derogation and non-narcissistic in-group positivity predicts positive attitudes toward out-groups.

Studies 1-3 examined the nature of non-narcissistic ingroup positivity, conceptualized as the importance of the ingroup to one's identity or positive evaluation of the in-group. These conceptualizations of positive group regard stem from the research tradition initiated by social identity theory and the subsequent differentiation between personal and collective self-esteem (see Crocker \& Luhtanen, 1990). A separate and vast literature has explored intergroup consequences of different forms of positive national feelings. In Study 4, we referred to this literature and examined the relationship between collective narcissism and different forms of patriotism.

\section{STUDY 4}

The aim of Study 4 was to demonstrate suppression effects with the conceptualization of positive group regard that refers to a national group specifically and distinguishes between constructive and blind forms of patriotism. Blind patriotism refers to an uncritical idealization of one's nation. Constructive patriotism, in contrast, is a high regard and concern for one's nation that does not avoid criticism but welcomes it as a spur toward betterment (e.g., Schatz etal., 1999). Of all the conceptualizations of in-group positivity that we reviewed above, constructive patriotism is the closest to what we mean by non-narcissistic in-group positivity. However, it is often conflated with blind patriotism and, as we argue, national collective narcissism. All variables overlap in positive attitudes toward a nation.

Blind patriotism and national collective narcissism overlap in uncritical idealization of the national in-group. However, blind patriotism is related to insensitivity to and avoidance of in-group criticism, whereas collective narcissism is related to increased sensitivity to signs of in-group criticism. Collective narcissists see threat to the in-group's image even in ambiguous acts and opinions of others and are preoccupied with validating and protecting the in-group's image.

In Study 4, we conducted our analysis considering both collective narcissism and blind patriotism as related but distinct forms of belligerent national identification. We first tested for suppression effects of constructive patriotism and collective narcissism. Then we tested whether a similar suppression effect would emerge for blind patriotism. Finally, we allowed blind patriotism and collective narcissism to compete against each other to act as suppressors for constructive patriotism and as predictors of negative attitudes toward out-groups.

\section{Method \\ Participants}

Participants were 267 Polish undergraduate students. The mean age was $24.96(S D=5.72)$; 239 participants were female and 22 were male ( 6 missing). All participants defined their nationality as Polish.

\section{Measures}

Constructive and blind patriotism. Constructive and blind patriotism were assessed using a Polish version of the scale developed by Schatz and colleagues (1999). A sample item for blind patriotism is "I would support my country right or wrong," whereas an example item for constructive patriotism is "If you love Poland, you should notice its problems and work 
to correct them." Participants were asked to provide their answers on a 7-point scale $(1=I$ strongly disagree and $7=I$ strongly agree; $\alpha=.76, M=2.29, S D=1.02$, for blind patriotism; $\alpha=.73, M=4.76, S D=1.06$, for constructive patriotism).

Collective narcissism. Collective narcissism was measured as in Studies 1 and $2(\alpha=.84, M=3.21, S D=.75)$.

Out-Group negativity. Out-group negativity toward Jews, Germans, and Russians was measured using the same semantic differentials as in Study 1 (all $\alpha_{\mathrm{S}}=.95$ ). The scores for the three out-groups were positively correlated (correlations ranging from .33 to .45 , all $p \mathrm{~s}<.001$ ). A composite score of negative out-group attitudes was computed $(\alpha=.94, M=3.82$, $S D=1.11)$.

\section{Results and Discussion}

The relationship between constructive patriotism and outgroup negativity was negative and nonsignificant, $r(259)=-.04$, $p=.54$. Blind patriotism was positively associated with outgroup negativity, $r(259)=.14, p=.02$. Collective narcissism was positively correlated with out-group negativity, $r(259)=21$, $p<.001$. Blind and constructive patriotism were positively related, $r(259)=.35, p<.001$. Collective narcissism was positively correlated with blind patriotism, $r(259)=.55, p<.001$, and with constructive patriotism, $r(259)=.52, p<.001$.

First, we tested for mutual suppression of constructive patriotism and collective narcissism. Out-group negativity was first regressed on constructive patriotism and collective narcissism independently. The relationship between constructive patriotism and out-group negativity was negative and nonsignificant. Collective narcissism alone significantly positively predicted out-group derogation (see Figure 4). Then out-group negativity was regressed on constructive patriotism and collective narcissism simultaneously. The full model was significant, $F(2,258)=10.22, R^{2}=.07, p=.01$. When collective narcissism was added to the equation containing only constructive patriotism, the negative relationship between constructive patriotism and out-group negativity strengthened and became significant, $b=-.20, S E=.07, p=.01$. The amount of explained variance increased significantly in comparison to the model with constructive patriotism as a sole predictor, $\Delta R^{2}=.07, p<.001$. When constructive patriotism and collective narcissism were analyzed together, the positive effect of collective narcissism on out-group negativity significantly strengthened, $b=.46, S E=.10, p<.001$. The amount of explained variance increased significantly in comparison to the model with collective narcissism as a sole predictor, $\Delta R^{2}=.03$, $p=.01$. The suppression effects of collective narcissism and constructive patriotism were significant (see Table 1).

Second, we tested whether blind and constructive patriotism show a similar mutual suppression pattern. Out-group negativity was first regressed on constructive patriotism and blind patriotism independently. Blind patriotism alone significantly positively predicted out-group derogation (see Figure 4). Then out-group negativity was regressed on constructive and blind patriotism simultaneously. The whole model was significant, $F(2,258)=3.92, R^{2}=.03, p=.02$. Adding blind patriotism to the regression equation significantly increased the amount of variance explained in out-group negativity, $\Delta R^{2}=.03, p=.01$. However, while the negative relationship between constructive patriotism and out-group negativity became stronger, it failed to reach statistical significance, $b=-.10, S E=.07, p=.12$. The positive relationship between blind patriotism and out-group negativity did not strengthen significantly when constructive patriotism was controlled for, $\Delta R^{2}=.01, p=.12$. It remained positive and significant, $b=.24, S E=.10, p=.01$.

Even though after controlling for blind patriotism the negative relationship between constructive patriotism and outgroup negativity did not reach significance, the suppression effect of blind patriotism on the relationship between constructive patriotism and out-group negativity was significant, with 95\% bias-corrected bootstrap confidence interval (CI) ranging from .02 to .13. However, the suppression effect of constructive patriotism on the relationship between blind patriotism and out-group negativity was not significant ( $95 \%$ biascorrected bootstrap CI ranged from -.12 to .02).

Finally, we included collective narcissism and the two types of patriotism in one model. We tested whether collective narcissism remains a significant suppressor of the relationship between constructive patriotism and out-group negativity when blind patriotism is controlled for. The full model was significant, $F(3,257)=7.04, R^{2}=.08, p<.001$. Compared to the three variables analyzed separately, when we included them in the same equation, (1) the negative relationship between constructive patriotism and out-group hostility became significant, (2) the positive relationship between blind patriotism and out-group negativity was reduced and became nonsignificant, and (3) the positive relationship between collective narcissism and out-group negativity was strengthened (see Figure 4).

The total suppression effect of blind patriotism and collective narcissism together was significant, with a bootstrap confidence interval of .09 to .27 . The specific suppression effect of collective narcissism was .15 and was significant, with $95 \%$ bias-corrected bootstrap CI ranging from .06 to .25 . The specific suppression effect of blind patriotism was .02 and was no longer significant, with $95 \% \mathrm{CI}$ ranging from -.03 to .08 .

We compared the equation containing all three predictors to the two predictor equations. Addition of collective narcissism to the equation initially containing only blind and constructive patriotism significantly increased the amount of explained variance in out-group hostility, $\Delta R^{2}=.05, p<.001$. However, the addition of blind patriotism to the equation initially containing only collective narcissism and constructive patriotism did not significantly increase the amount of explained variance, $\Delta R^{2}=.002, p=.41$.

The results of Study 4 indicate that after narcissistic aspects of national attachment are controlled for, the negative 


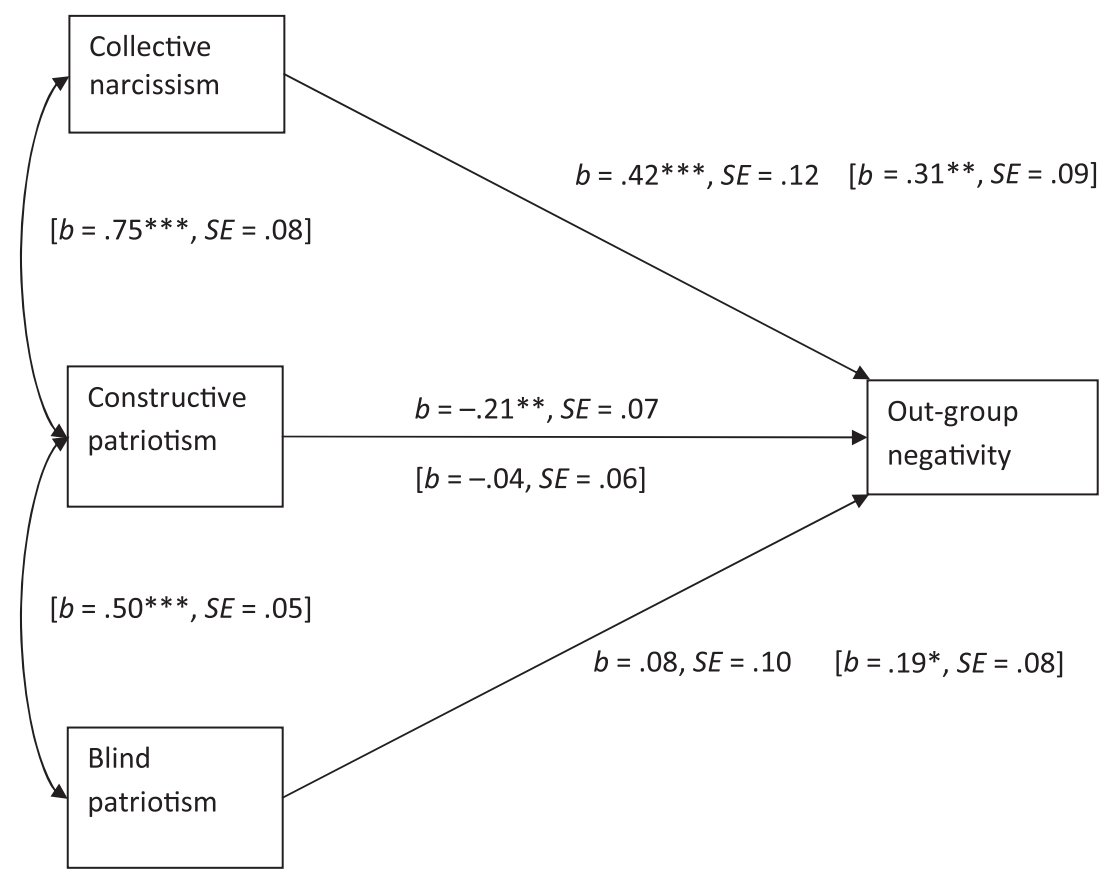

Figure 4 Suppression effects of collective narcissism and constructive patriotism on out-group negativity, controlling for blind patriotism (Study 4; N=26I). Entries are unstandardized regression coefficients. Results for simple regressions are presented in brackets.

$* p<.05$. **p $<.01$. *** $p<.001$.

relationship between constructive patriotism and out-group hostility becomes significant whether or not blind patriotism is also accounted for. In addition, when collective narcissism is entered into the equation, blind patriotism no longer significantly suppresses the negative relationship between constructive patriotism and out-group derogation. Moreover, the positive relationship between blind patriotism and out-group derogation becomes nonsignificant.

Thus far, the present studies provide support for our theoretical propositions. The mutual suppression pattern generalizes to different national contexts and different conceptualizations and operationalizations of in-group positivity. However, all of our studies investigated the relationships between narcissistic and non-narcissistic in-group positivity and out-group negativity in the context of national groups. Nonetheless, we propose that this pattern of relationships can be extended beyond this context. People form positive attachments to different social groups, and we should be able to differentiate between genuine and narcissistic in-group favoritism with reference to groups other than nations (see Golec de Zavala etal., 2009). Thus, in Study 5, we examined collective narcissistic and in-group positivity with reference to a group defined as students of the same university. We examined their relationships with negative attitudes toward students from other universities perceived as comparable, competing and threatening one's own university's position in the national League Tables. We expected to find the same pattern of mutual suppression as revealed in studies regarding national in-group positivity.

\section{STUDY 5}

\section{Method}

\section{Participants}

Participants were 241 undergraduate students of the same university based in London. The mean age was $23.10(S D=5.65)$; 55 participants were male, 185 were female, and one participant did not report gender. Forty-two percent of participants were White, $23 \%$ were Black, $5 \%$ indicated a mixed identity, $27 \%$ identified as "other," and $3 \%$ did not report ethnicity.

\section{Measures}

In-group identification. In-group identification $(\alpha=.80$, $M=4.04, S D=1.41$ ) was measured with four items used previously by Crisp etal. (2006; e.g., "I identify strongly with my university"). Responses could range from 1 (strongly disagree) to 7 (strongly agree).

Collective narcissism. Collective narcissism $(\alpha=.82$, $M=3.33, S D=1.16$ ) was measured by the Collective Narcissism Scale (Luhtanen \& Crocker, 1992) with reference to students from one's own university.

Out-group negativity. Out-group negativity was measured using Feeling Thermometers. Participants were asked how they felt about students from other universities studying at their university as exchange students. The scale ranged from $0^{\circ}$ (extremely unfavorable) to $100^{\circ}$ (extremely favorable). The 
data were recoded so that higher scores indicate more negative feelings toward out-groups. Feelings toward students of three competing universities in the same city were analyzed. The scores were positively significantly correlated (Pearson's $r$ ranging from .47 to .54 , all $p s<.001)$. A composite score of out-group attitudes was constructed $(\alpha=.80, M=49.93$, $S D=21.70)$.

\section{Results and Discussion}

The relationship between in-group identification and outgroup negativity was negative and nonsignificant, $r(227)=-.11$, $p=.09$. Collective narcissism was positively correlated with out-group negativity, $r(227)=.14, p=.04$. Collective narcissism was positively correlated with in-group identification, $r(236)=.36, p<.001$.

Out-group negativity was first regressed on in-group identification and on collective narcissism independently. The relationship between in-group identification and out-group negativity was negative and nonsignificant. Collective narcissism significantly positively predicted out-group negativity. Then the out-group negativity was regressed on both predictors entered together. The full model was significant, $F(2$, $226)=5.93, R^{2}=.05, p=.003$. When collective narcissism was added to the equation, the initial negative relationship between in-group identification and out-group negativity became significant, $\Delta R^{2}=.04, p=.003$. The initial positive relationship between collective narcissism and out-group negativity significantly strengthened when group identification was added to the equation already containing collective narcissism, $\Delta R^{2}=.03$, $p=.01$ (see Figure 5). The suppression effects of collective narcissism and in-group positivity were significant (see Table 1).

The results of Study 5 confirm that the pattern of mutual suppression involving the relationships between narcissistic and positive in-group regard and out-group derogation can be found in the context of social groups other than the national in-group.

\section{GENERAL DISCUSSION}

The findings from the current studies demonstrated that collective narcissism was positively related to various forms of positive in-group regard: high collective self-esteem (Study 1), high in-group identification (Studies 2 and 5), positive affect, strong ties with and high centrality of the in-group to the self (Study 3), and constructive patriotism (Study 4). When the overlap between collective narcissism and positive group regard was not controlled for, positive group regard showed no significant or consistent relation with out-group negativity, corroborating the results of previous reviews and meta-analyses (e.g., Hinkle \& Brown, 1990; Jackson et al., 2001; Pehrson etal., 2009). However, when the common variance of collective narcissism and positive in-group regard was partialed out, narcissistic and non-narcissistic aspects of in-group positivity had independent, significant, and opposed relationships with out-group derogation. The present results suggest that existing measures and conceptualizations of in-group positivity tap different aspects of the overlap between narcissistic and nonnarcissistic in-group positivity, resulting in positive, negative, or null relationships with out-group negativity.

The present results indicate-with remarkable consistency across studies, countries, and intergroup contexts - that controlling for the positive overlap between collective narcissism and in-group positivity allows us to uncover the fact that genuine, non-narcissistic in-group positivity predicts positive attitudes toward out-groups. Thus, people who appreciate their in-group are able to appreciate other groups. However, because in-group positivity is positively related to collective narcissism, a tendency to form hostile attitudes toward out-groups associated with collective narcissism masks the potential of unpretentious and noncontingent positive in-group regard to predict positive attitudes toward out-groups.

It is also noteworthy that the negative relationship between in-group positivity and out-group negativity indicates that low in-group positivity is related to intergroup bias. Thus, it may be the case that people who are not narcissistic about their

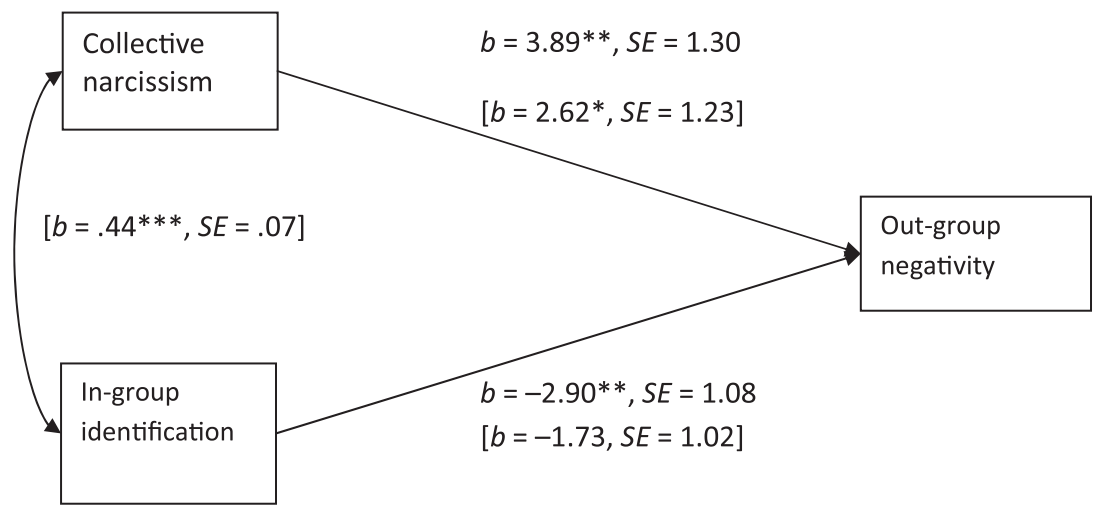

Figure 5 Suppressor effect of in-group identification and collective narcissism on out-group negativity (Study 5; N=24I). Entries are unstandardized regression coefficients. Results for simple regressions are presented in brackets.

$* p<.05$. **p $<.01$. *** $p<.001$. 
in-group derogate out-groups to enhance their positive opinion about the in-group. Narcissistic exaggeration of the in-group's greatness and low group esteem are likely to be linked to outgroup derogation for different reasons and through different processes. Understanding of these processes requires further studies. Previous research on collective narcissism advances our understanding of the possible mechanisms beyond the link between collective narcissism and out-group negativity and its potential to reduce the relationship of non-narcissistic ingroup positivity with positive out-group attitudes.

We believe that the fact that narcissistic in-group positivity is not only high but also inherently insecure is responsible for the link between collective narcissism and out-group negativity. Narcissists require constant external appreciation and are threatened by criticism or even lack of sufficient recognition of their positive self-image. Narcissists respond with aggression to ego threats (e.g., Bushman \& Baumeister, 1998). Studies demonstrate that similar responses occur in the case of collective narcissism. Collective narcissists believe their group is not as appreciated by others as by oneself. Collective narcissism is related to lack of positive preference for the ingroup over other groups on an implicit level. In addition, collective narcissism predicts perception of ambiguous intergroup situations as threatening and retaliatory intergroup hostility in response to group-based criticism (Golec de Zavala etal., 2009).

The social identity literature does provide evidence that it is not just in-group positivity but threatened in-group positivity that explains people's attitudes and behavior toward outgroups (Branscombe \& Wann, 1994; Branscombe, Wann, Noel, \& Coleman, 1993; Ellemers, Spears, \& Doosje, 2002). Our research sheds some light on the specific form of in-group positivity that is built around chronic threat to the in-group's exaggerated greatness. When the narcissistic aspect of ingroup positivity is teased out, the non-narcissistic in-group positivity provides a basis for secure relations with out-groups.

Interestingly, the present results confirm and extend into the intergroup level the findings that individual narcissism and personal self-esteem suppress each other's relationships with interpersonal anger, aggression, and delinquent behavior (e.g., Donnellan etal., 2005; Paulhus etal, 2004). In this way, they corroborate theorizing and empirical evidence indicating that psychological processes related to personal identity have their parallels in processes related to social identity (e.g., Bizman, Yinon, \& Krotman, 2001).

The present results confirm that positive group regard can be linked to either positive or negative out-group attitudes depending on whether it takes narcissistic or non-narcissistic form. Existing differentiations between more and less belligerent forms of positive national feelings (e.g., Kosterman \& Feshbach, 1989; Schatz etal., 1999) do not systematically uncover the potential of constructive national feelings to predict positive attitudes toward national minorities and national out-groups. Only after the overlap between collective narcissism and constructive patriotism was partialed out (with or without also taking the overlap with blind patriotism into account) did a significant negative relationship between constructive patriotism and out-group negativity emerge in Study 4.

In addition, the results of Study 4 indicate that the narcissistic aspect of blind patriotism seems to be responsible for its intergroup effects. This suggests that intergroup hostility of blind patriots may be a defensive and retaliatory response to in-group image threat. Thus, unlike in the case of nationalistic intergroup hostility, intergroup hostility associated with blind patriotism does not seem to serve the purpose of achieving a dominant in-group position borne out of competitiveness. Importantly, our results also indicate that the differentiation of the narcissistic in-group positivity can be extended beyond the context of national groups to groups as mundane as one's university affiliation. To our knowledge, this is the first evidence of this effect.

Finally, corroborating the results of previous studies, collective narcissism systematically predicted out-group hostility across five studies. However, the present results go beyond the previous findings. They indicate that partialing out the relationship collective narcissism has with genuine in-group positivity significantly strengthened the positive relationship between collective narcissism and out-group negativity. Thus, there is something about non-narcissistic in-group positivity that mitigates the relationship between collective narcissism and out-group negativity. We can hypothesize that the experience of developing secure pride and positive concern for an in-group can help develop respect for other groups. It is also possible that mature love for an in-group might be a developmental achievement that requires overcoming group-centrism. Further studies are needed in order to better understand the role of positive in-group attachment in the development of positive attitudes toward other groups. So far, this important domain has been neglected because research has focused on the opposite relationship.

\section{References}

Aberson, C. L., Healy, M. R., \& Romero, V. L. (2000). In-group bias and self-esteem: A meta-analysis. Personality and Social Psychology Review, 4, 157-173.

Abrams, D., \& Hogg, M. A. (1988). Comments on the motivational status of self-esteem in social identity and intergroup discrimination. European Journal of Social Psychology, 18, 317-334.

Alwin, D. (1997). Feeling thermometers versus 7-point scales: Which are better? Sociological Methods and Research, 25, 318-340.

Baumeister, R. F., Campbell, J. D., Krueger, J. I., \& Vohs, K. D. (2003). Does high selfesteem cause better performance, interpersonal success, happiness, or healthier lifestyles? Psychological Science in the Public Interest, 4, 1-44.

Bizman, A., Yinon, Y., \& Krotman, S. (2001). Group-based emotional distress: An extension of self-discrepancy theory. Personality and Social Psychology Bulletin, 27, 1291-1300. 
Bogardus, E. S. (1925). Social distance and its origins. Sociology and Social Research, 9, 216-225.

Bowlby, J. (1982). Attachment and loss: Attachment (Vol. 1, 2nd ed.). New York: Basic Books.

Branscombe, N. R., \& Wann, D. L. (1994). Collective self-esteem consequences of outgroup derogation when a valued social identity is on trial. European Journal of Social Psychology, 6, 641-657.

Branscombe, N. R., Wann, D. L., Noel, J. G., \& Coleman, J. (1993). In-group or out-group extremity: Importance of the threatened social identity. Personality and Social Psychology Bulletin, 19, 381-388.

Bushman, B. J., \& Baumeister, R. (1998). Threatened egotism, narcissism, self-esteem, and direct and displaced aggression: Does selflove or self-hate lead to violence? Journal of Personality and Social Psychology, 75, 219-229.

Byron, G. (1822). Two Foscari: An historical tragedy. Paris: Galignani.

Cameron, J. (2004). A three-component model of social identification. Self and Identity, 3, 239-262.

Cohen, J., Cohen, P., West, S. G., \& Aiken, L. S. (2003). Applied multiple regression/correlation analysis for the behavioral sciences. London: Erlbaum.

Conger, A. J. (1974). A revised definition for suppressor variables: A guide to their identification and interpretation. Educational Psychological Measurement, 34, 35-46.

Crisp, R. J., Stone, C. H., \& Hall, N. R. (2006). Recategorization and subgroup identification: Predicting and preventing threats from common ingroups. Personality and Social Psychology Bulletin, 32, 230-242.

Crocker, J., \& Luhtanen, R. (1990). Collective self-esteem and ingroup bias. Journal of Personality and Social Psychology, 58, 60-67.

de Figueiredo, R. J. P., \& Elkins, Z. (2003). Are patriots bigots? An inquiry into the vices of ingroup pride. American Journal of Political Science, 47, 171-188.

Donnellan, M. B., Trzesniewski, K. H., Robins, R. W., Moffitt, T. E., \& Caspi, A. (2005). Low self-esteem is related to aggression, antisocial behavior, and delinquency. Psychological Science, 16, 328-335.

Ellemers, N., Spears, R., \& Doosje, B. (2002). Self and social identity. Annual Review of Psychology, 53, 161-186.

Fairchild, A. J., MacKinnon, D. P., Taborga, M. P., \& Taylor, A. B. (2009). $R^{2}$ effect-size measures for mediation analysis. Behavior Research Methods, 41, 486-498.

Fritz, M. S., \& MacKinnon, D. P. (2007). Required sample size to detect the mediated effect. Psychological Science, 18, 233-239.

Goff, P. A., Steele, C. M., \& Davies, P. G. (2008). The space between us: Stereotype threat and distance in interracial contexts. Journal of Personality and Social Psychology, 94, 91-107.

Golec de Zavala, A. (2011). Collective narcissism and intergroup hostility: The dark side of "in-group love." Social and Personality Psychology Compass, 5, 309-320.

Golec de Zavala, A., \& Cichocka, A. K. (2011). Collective narcissism, intergroup threat and intergroup hostility: The role of threatened collective egotism. Manuscript submitted for publication.

Golec de Zavala, A., \& Cichocka, A. K. (2012). Collective narcissism and anti-Semitism in Poland. Group Processes and Intergroup Relations, 15, 213-229.

Golec de Zavala, A., Cichocka, A. K., Eidelson, R., \& Jayawickreme, N. (2009). Collective narcissism and its social consequences. Journal of Personality and Social Psychology, 97, 1074-1096.

Hayes, A. F. (2009). Beyond Baron and Kenny: Statistical mediation analysis in the new millennium. Communication Monographs, 76, 408-420.

Hinkle, S., \& Brown, R. (1990). Intergroup comparisons and social identity: Some links and lacunae. In D. Abrams \& M. Hogg (Eds.), Social identity theory: Constructive and critical advances (pp. 48-70). Hemel Hempstead, England: Harvester Wheatsheaf.

Hunter, J., Cox, S., O’Brien, K., Springer, M., Boyes, M., Banks, M., etal. (2005). Threats to group value, domain-specific self-esteem and intergroup discrimination amongst minimal and national groups. British Journal of Social Psychology, 44, 329-353.

Jackson, J. S., Brown, K. T., Brown, T. N., \& Marks, B. (2001). Contemporary immigration policy orientations among dominantgroup members in Western Europe. Journal of Social Issues, 57, 431-456.

Kosterman, R., \& Feshbach, S. (1989). Toward a measure of patriotic and nationalistic attitudes. Political Psychology, 10, 257-274.

Long, K. M., \& Spears, R. (1998). Opposing effects of personal and collective self-esteem on interpersonal and intergroup comparisons. European Journal of Social Psychology, 28, 913-930

Luhtanen, R., \& Crocker, J. (1992). A collective self-esteem scale: Self-evaluation of one's social identity. Personality and Social Psychology Bulletin, 18, 302-318.

MacKinnon, D. P., Krull, J. M., \& Lockwood C. M. (2000). Equivalence of the mediation, confounding and suppression effect. Prevention Science, 1, 173-181.

McCleary, D. F., Nalls, M. L., \& Williams, R. L. (2009). Types of patriotism as primary predictors of continuing support for the Iraq War. Journal of Political and Military Sociology, 37, 77-94.

Paulhus, D. L., Robins, R. W., Trzesniewski, K. H., \& Tracy, J. L. (2004). Two replicable suppressor situations in personality research. Multivariate Behavioral Research, 39, 303-328.

Pehrson, S., Brown, R., \& Zagefka, H. (2009). When does national identification lead to the rejection of immigrants? Cross-sectional and longitudinal evidence for the role of essentialist ingroup definitions. British Journal of Social Psychology, 48, 61-76.

Preacher, K. J., \& Hayes, A. F. (2004). SPSS and SAS procedures for estimating indirect effects in simple mediation models. Behavior Research Methods, Instruments, and Computers, 36, 717-731.

Preacher, K. J., \& Hayes, A. F. (2008a). Asymptotic and resampling strategies for assessing and comparing indirect effects in multiple mediator models. Behavior Research Methods, 40, 879-891.

Preacher, K. J., \& Hayes, A. F. (2008b). Contemporary approaches to assessing mediation in communication research. In A. F. Hayes, M. D. Slater, \& L. B. Snyder (Eds.), The Sage sourcebook of 
advanced data analysis methods for communication research (pp. 13-54). Thousand Oaks, CA: Sage.

Preacher, K. J., \& Kelley, K. (2011). Effect size measures for mediation models: Quantitative strategies for communicating indirect effects. Psychological Methods, 16, 93-115.

Rubin, M., \& Hewstone, M. (1998). Social identity theory's selfesteem hypothesis: A review and some suggestions for clarification. Personality and Social Psychology Review, 2, 40-62.

Schatz, R. T., Staub, E., \& Lavine, H. (1999). On the varieties of national attachment: Blind versus constructive patriotism. Political Psychology, 20, 151-174.
Tajfel, H., \& Turner, J. C. (1986). The social identity theory of intergroup behavior. In S. Worchel \& L. W. Austin (Eds.), Psychology of intergroup relations (pp. 7-24). Chicago: Nelson-Hall.

Tzelgov, J., \& Henik, A. (1991). Suppression situations in psychological research: Definitions, implications, and applications. Psychological Bulletin, 109, 524-536.

Wright, S., Aron, A., McLaughlin-Volpe, T., \& Ropp, S. A. (1997). The extended contact effect: Knowledge of cross-group friendships and prejudice. Journal of Personality and Social Psychology, 73, 73-90. 